\title{
Potential contribution of aspirin to cancer control programmes
}

\section{G Morgan}

Welsh Aspirin Group Secretary, 41 Fforrd Beck, Gowerton, Swansea, Wales SA4 3GE, UK

\begin{abstract}
Chemoprevention describes the potential of chemicals to intervene and block multi-stage carcinogenesis. Aspirin (acetylsalicylate) is showing cancer chemopreventive potential and the medicine has public health potential given that low doses also reduce the risk of cardiovascular events by up to $30 \%$. Whilst recognizing that aspirin has undesirable effects, such as increasing the risk of stomach bleeding, perhaps the medicine may compliment other cancer control programmes such as screening and lifestyle measures. Furthermore, perhaps the cancer chemopreventive potential of aspirin might be mediated, at least in part, by salicylate, which is present in fruits and vegetables. Salicylate might, therefore, be considered to be a nutraceutical. Furthermore, there are a number of matters that arise including the potential for the public health field to further advocate the self-care preventive agenda, which might include aspirin. Perhaps, it is now timely for a conference on the public health potential of aspirin to be convened.
\end{abstract}

Published: 12/11/2008

Received: $12 / 10 / 2008$

ecancer 2008, 2:100 DOI: 10.3332/ecancer.2008.100

Copyright: (c) the authors; licensee ecancermedicalscience. This is an Open Access article distributed under the terms of the Creative Commons Attribution License (http://creativecommons.org/licenses/by/2.0), which permits unrestricted use, distribution, and reproduction in any medium, provided the original work is properly cited.

Competing Interests: The authors have declared that no competing interests exist.

Correspondence to G Morgan. Email: morgan@fforrdbeck.fsnet.co.uk 


\section{Introduction}

Chemoprevention describes the potential of pharmaceutically manufactured or naturally produced chemicals to intervene and block the complex processes of cancer formation, so called multi-stage carcinogenesis [1]. A number of chemicals with cancer chemopreventive potential have been reported in the literature, such as curcumin [2] and ginseng [3]. Some medicines in clinical use also have cancer chemopreventive properties, for example retinoids decrease the numbers of squamous cell skin carcinomas in psoriasis patients [4], and tamoxifen is used for breast cancer risk reduction in patients in remission from the disease [5].

Aspirin (acetylsalicylic acid) is an easily obtainable and inexpensive pharmaceutical medicine that is widely used to treat a number of conditions [6]. The chemical of acetylsalicylic acid was first synthesized in 1899 by Bayer Pharmaceuticals in Germany [7] and mass produced under the commercial name of aspirin. In the intervening century, aspirin has become one of the most widely used medicines around the world and it is also showing cancer chemopreventive potential [8]. The interest in this potential extends back over more than a decade and aspirin and other non-steroidal anti-inflammatory drugs (NSAIDs) were the subject of the first International Agency for Research on Cancer (IARC) scientific evaluation on cancer chemoprevention [9].

Since the IARC evaluation, selective NSAIDs have been introduced into clinical use in an attempt increase the effectiveness of this class of medicines. Some of these selective agents, such as celecoxib, offer a chemopreventive rather than surgical option against pre-cancerous adenomatous polyps in the bowel $[10,11]$. However, selective NSAIDs are associated with an increased risk of cardiovascular events $[10,11]$, which raises questions about the benefit-versus-risk balance of these medicines. Such benefit-versus-risk questions would appear to make selective NSAIDs unsuitable for cancer chemoprevention in the general population.

It might be reasonably argued that of all existing and emerging cancer chemopreventive agents, aspirin has the greatest public health potential. Low-dose aspirin prophylaxis, $70-150 \mathrm{mg} / \mathrm{d}$, reduces the risk of cardiovascular events by up to $30 \%$ [12]. Furthermore, aspirin is already well known and widely used in the general population as well as providing a benchmark to measure the effectiveness of other medicines, such as statins [13]. However, aspirin also has undesirable effects [14], most notably irritation and bleeding of the stomach. Occasionally, these undesirable effects can be serious and may even be fatal in some cases [14]. Aspirin prophylaxis against cardiovascular events therefore balances benefit and risk. The emerging evidence on aspirin and cancer chemoprevention, particularly bowel cancer, is also a relevant consideration in this benefit and risk assessment.

\section{Aspirin, salicylates and cancer}

Randomized controlled trials (RCTs) provide evidence that aspirin reduces recurrence of either adenomatous polyps or pathological changes associated with an increased risk of bowel cancer $[15,16]$. The limitation to the RCTs, however, is that they only use a proxy outcome measure rather than cancer as the end point. With reference to RCTs on aspirin and cancer, there is a variation in results between trials. Two trials in the United States provided no evidence that aspirin on alternate days reduces cancer risk $[17,18]$. By contrast, a re-evaluation of two trials in the United Kingdom with daily aspirin found that ten years of use reduced the risk of bowel cancer by $40 \%$ [19]. Although different doses were used in the four trials, one of the US trials and one of the UK trials used similar doses of 325 and $300 \mathrm{mg}$, respectively. Furthermore, one of the US trials also had a follow-up of ten years, which raises questions about the dose and duration effect of aspirin.

Possibly, the difference in the results between the US and UK trials might be due, at least in part, to the different dosing regimes of alternate days versus daily, respectively. Possibly, daily aspirin exposure over ten years might be required to reduce the risk of bowel cancer. Furthermore, the current evidence suggests that perhaps doses of aspirin higher than those used routinely for cardiovascular event prophylaxis might be required for chemoprevention. The risk of undesirable effects from aspirin increases with both age and dose. This is an important point given that many cancers, such as bowel cancer, tend to have rising incidence in the general population with increasing age.

Perhaps, there might also be another dimension with the possible cancer chemopreventive effects of aspirin. The potential cancer chemopreventive effects might be related, at least in part, to salicylate. Humans are exposed to salicylate through eating fruit and vegetables, and it has been suggested that perhaps salicylate might be beneficial to health [20]. Salicylate has anti-oxidant effects, anti-inflammatory properties and induces programmed cell death or apoptosis in cancer cells [21]. More evidence is needed on the effect of salicylate on 
human health generally and cancer chemoprevention specifically. This also raises a wider issue of whether components of food can be helpful in reducing disease risk.

Nutraceuticals are a food, or part of a food, that provides medical or health benefits, including the prevention or possibly treatment of a disease [22]. The term nutraceutical is a hybrid of nutrition and pharmaceutical [23]. It has been suggested that a 'nutraceutical a day may keep the doctor away' and that 'consumers are turning increasingly to food supplements to improve well being when pharmaceuticals fail' [23]. This however raises further issues given that there is evidence that supplements of some vitamins may increase the risk of premature mortality [24]. A clear scientific definition of the criteria for vitamin status and also the introduction of a regulatory system for their supply and demand might be some of the developments taken forward.

In future, there might be more attention given to the potential value of nutraceuticals in the promotion of human health. There are numerous examples of nutraceuticals published in the literature and, for example, these have relevance to the chemoprevention of stomach [25] and prostate [26] cancers. Poly-unsaturated fatty acids (PUFAs) have anti-inflammatory effects [27] and since chronic low-level inflammation can increase the risk of some cancers [28], perhaps both PUFAs and salicylates may have cancer chemopreventive properties. As a related point, inflammation in vascular tissue also appears to be an aetiological factor in cardiovascular events $[29,30]$.

Research therefore appears to be warranted on whether salicylate derived from fruit and vegetables has nutraceutical properties. Such research may contribute to a wider debate on dietary changes in the population. So-called epidemiological diet transition suggests that populations are eating more processed foods and less fruit and vegetables [31]. Possibly, reduced dietary intake of salicylate in the population might predispose some individuals to increased cancer risk and perhaps aspirin might counteract this deficiency. This may also provide further reasons to promote the intake of salicylate rich fruit and vegetables, such as berries and organic produce, in the general population. However, it also needs to be recognized that chemoprevention might be only one element of cancer control programmes, alongside other measures such as screening and lifestyle approaches.
Screening is one of the important cancer control programmes. In screening, individuals are asked a question or offered a test to identify those who might be helped by further investigation. Screening programmes include breast and bowel cancers. Taking the former, a review of breast cancer screening by the evidence-based body, the Cochrane Collaboration, suggested that the programme of mammography in women over the age of 50 years lowers risk of breast cancer mortality by about $15 \%$ [32]. However, the review also highlighted that there are some undesirable aspects of breast cancer screening for some women. This includes inaccurate results leading to unnecessary treatment for some women. The review called for women who are invited to breast cancer screening to be 'fully informed of both benefits and harms'. This statement also appears to be pertinent to aspirin prophylaxis since the medicine also has benefits and risks. There is also some promising evidence that aspirin may also reduce the risk of breast cancer [33] although, similar to bowel cancer, low doses on alternate days may not have chemopreventive effects [34].

One of the limitations to the breast cancer screening programme is that younger women at increased risk of the disease are not routinely included [35]. Family history of breast cancer is a strong predictor of disease development and is one of the factors used in compiling at risk registers for women. Such registers can then be used to follow up women at increased risk of breast cancer and in addition, primary care has been highlighted as a potential setting to identify those who may have hereditary predisposition to the disease, such as BRCA mutation carriers [36].

With respect to the bowel cancer screening programme, this includes the faecal occult blood test (FOBT). Similar to the breast cancer programme, a Cochrane Collaboration review has highlighted the potential undesirable aspects of inaccurate results and unnecessary treatment [37]. Bowel cancer screening programmes vary in their delivery, but they also usually include individuals over the age of 50 years. In addition, younger high-risk patients who are genetically predisposed to bowel cancer are usually identifiable, and in the United Kingdom they are often registered with a Regional Genetics Centre. Highrisk patients include those with genetic conditions, including hereditary non-polyposis colorectal cancer (HNPCC) and familial adenomatous polyposis (FAP). HNPCC patients usually receive surveillance of the bowel from the age of 25 years,

\section{Other cancer control programmes}


whilst in the case of FAP, prophylactic surgery before the age of 25 years is usually recommended [38].

One of the issues with the bowel cancer screening programme relates to the screening algorithm based upon FOBT and colonoscopy for those testing positive, with perhaps radiology also contributing in future [39]. Although FOBT is a simple and non-invasive test, it has poor sensitivity and may only detect a bleeding lesion rather than cancerous changes [40]. Furthermore, colonoscopy rather than FOBT may be the most appropriate initial investigation for individuals with higher than average risk of bowel cancer [41]. In developing bowel cancer screening programmes, considerations include patient preferences, likelihood of adherence to follow up and resources available [42].

Another issue with the bowel cancer screening programme relates to uptake. For example in the UK Bowel Cancer Screening Pilot Programme, nearly 130,000 men and women aged 50-69 years were invited to participate and uptake ranged from $61 \%$ in the wealthiest areas to $37 \%$ in the poorest areas [43]. Does this mean that screening should be more intensively targeted in the areas of lowest uptake? This possibility does deserve to be considered although the UK Bowel Cancer Screening Programme is already financially constrained [44] so intensive targeting may not be a possibility within available resources.

Self-care is important [45] and perhaps consideration could be given to the potential contribution of aspirin to bowel cancer screening programmes. Individuals who have pre-cancerous lesions removed from the bowel in the programme might at least be offered the evidence on the benefits and risks of lowdose aspirin given that this might reduce the risk of subsequent pathological changes associated with bowel cancer development. There is an important related dimension to this. Many individuals at the age of 50 have a risk of cardiovascular events in which considering taking low-dose aspirin prophylaxis may be a reasonable option [46,47], although this possibility has been debated [48]. It may be recognized, however, that cardiovascular events and cancer are the biggest causes of disease, disability and death in the population, and so increased use of aspirin might confer considerable public health benefits if targeted appropriately [49].

It may be reasonably concluded that cancer screening programmes do not represent a complete solution to cancer control and do have negative aspects as well. So in addition to screening programmes, there are also lifestyle approaches to cancer control. For example the deleterious effects of smoking on health and the importance of cessation have been well documented, especially within the context of deprivation and low socio-economic status in which the highest smoking rates are found [50]. Gender may also play an important role as well, since there is suggestive evidence that women might be more susceptible to developing smoking-related illnesses compared with men [51]. Whilst smoking cessation programmes are important, other measures such as advertising bans on tobacco products might also contribute to cancer control programmes [52].

Alcohol consumption is sometimes closely associated with smoking [53] and even moderate alcohol consumption may increase the risk of some cancers, such as breast. This increased risk, however, conflicts with health promotion advice on moderate alcohol consumption for the cardiovascular benefits [54]. Cancer control programmes therefore need to find a balance between the benefits and risks of alcohol consumption, which raises wider social considerations.

Diet is also important, and IARC are co-ordinating the European Prospective Investigation into Cancer and Nutrition study across ten countries. This includes more than half a million participants of whom $70 \%$ are men between the ages of 35 and 70 years. This study shows the impact of diet on cancer risk [55], for example, vegetables, which contain salicylate, appear to reduce the risk of stomach cancer. In addition, red meat appears to increase the risk of bowel cancer whilst fish, which contain PUFAs, may decrease the risk of the disease. Furthermore, there is evidence that obesity is a risk factor for cancer as well, for example breast and bowel cancers in post-menopausal women [56]. This highlights the potential importance of both diet and exercise in reducing cancer risk through a process of weight control.

However, two publications, of relevance to weight control, illustrate the complexity of lifestyle approaches to reducing the risk of cancer. In November 2007, a World Cancer Research Fund (WRCF) report set out ten rules for preventing cancer [57]. One of these rules was having a Body Mass Index (BMI) of 25 or lower. Shortly after the publication of WRCF report, the US Centers for Disease Control and Prevention (CDC\&P) also presented cancer control recommendations [58]. This report provided evidence that being underweight and obesity carry increased risks of mortality, albeit from different causes. Furthermore, it was suggested that being overweight, defined as having a BMI of between 25-30, was associated with decreased mortality overall and was not associated with mortality from either cancer or cardiovascular causes.

With both of the WRCF and CDC\&P reports, the media coverage was extensive and to some extent contradictory. This 
contradiction appears to be consistent with the comment of the Public Library of Science Medical Editors, who stated: 'It is not always easy for the public to determine what is best given the barrage of information forced on them every week' [59]. Lessons from other medical issues also highlight the need for health professionals to provide the general public with clear and consistent information. For example, in 1998, a controversial study linked measles, mumps and rubella (MMR) with autism [60], and this was widely reported in the media. Since 1998, the uptake of MMR vaccination has declined and a study on the reasons has suggested that inadequate information from healthcare professionals was an important contributory factor [61].

If lifestyle approaches to cancer control are to be fully maximized then it is important for the general public to be given clear and consistent information by healthcare professionals. This is pertinent to aspirin. If the general public is to be given clear and consistent information on ways to reduce the risk of cancer, at what stage is the emerging evidence on aspirin systematically put into the public domain to allow individuals to make their own informed decisions on whether or not to take aspirin? This is a far reaching question that deserves to be debated further, particularly since the information on aspirin and cancer is already being reported in the media with differing levels of accuracy.

For the purposes of comprehension, the use of vaccines to reduce cancer risk also merits brief mention to illustrate the broader context of cancer control programmes. For example, the human papillomavirus (HPV) is a sexually transmitted infection, which causes genital warts and some cancers, most notably cervical cancer. HPV vaccination programmes to reduce the risk of cervical cancer may be seen as a complement rather than an alternative to the screening programme for this disease [62]. Although some issues still need to be given further consideration with HPV vaccination, including the duration of protection [63], the broader point with wider application is that different cancer control approaches can be combined.

\section{From preventive self-care to public health policy}

The population is ageing and with individuals living longer, service provision is becoming increasingly community based [64] and multi-disciplinary [65] in some countries. In addition to the changing patterns of service provision, self-care is important
[66], and this has the potential to improve the management of long-term conditions whilst also taking account of patient safety issues [67]. The potential of self-care, however, also extends to prevention as well as self-examination for the early identification of testicular cancer. It has also been stated that an 'ounce of prevention is worth a pound of cure' and one way to achieve this may be to 'offer financial incentives to people for healthy behaviour' [68]. This is a controversial suggestion that could have far reaching implications for the delivery of public health policy.

Public health may be considered as improving and protecting the health of groups of people, or populations, rather than treating individual patients. Public health has a proud tradition [69], for example in 1848, the Public Health Act for England and Wales [70] and Sir Edwin Chadwick, the driving force behind this Act, has been described as leaving a 'monumental' public health legacy [71]. Although some have argued that public health is in decline [72,73], the framework for the delivery of public health continues to evolve [74]. So perhaps there is an opportunity for the field of public health to further advocate the self-care preventive agenda, which might include aspirin. This could be progressed through collaborative working, which has been suggested as an important leadership issue in public health [75], for example in the so-called communities of practice with other professional groups [76].

It is reasonable to acknowledge that there is a considerable amount of knowledge on lifestyle risk factors for disease. For example a cohort study of 20,000 men and women aged 45-79 years in east England is part of the IARC European Prospective Investigation on Cancer and Nutrition study. The study has suggested that regular exercise, 1-14 units of alcohol per week (unit = glass of wine or half pint of beer), eating five servings of fruits and vegetables per day and not currently smoking might prolong life by 14 years [77]. The public health potential of aspirin might be viewed as complement rather than an alternative or competitor to these beneficial lifestyle factors. However, the potential increased use of the medicine still raises a number of debates and ethical considerations [78], some of which may be presented to the public through the media.

In balance to the two illustrations of media interest in health issues presented previously, it may be acknowledged that media involvement can be beneficial. For example, in Wales, the bowel cancer screening programme was launched at the end of October 2008. Television advertising was used as one of the methods to raise awareness of both the disease and the screening programme. Perhaps the wider lesson is that close 
working between media and health professionals can usefully disseminate accurate information to the benefit of the targeted population.

\section{Conclusion}

Currently, there is a trend towards an increase in life expectancy in the population, which appears to be attributable to improvements in medicine, public health and agriculture [79]. The two biggest causes of disease, disability and death in the population are cardiovascular disease and cancer, and increased aspirin use might reduce their burden. The increased use of aspirin may in future form part of cancer control programmes and the increased use of the medicine in the population may confer considerable public health benefits. These benefits could lead to a further shift towards preventive self-care, which might in turn help reduce the pressure on healthcare services. Indeed, even the iconic National Health
Service in the United Kingdom has limitations in caring for the population over the age of 50 years [80]. So there might be considerable population need, defined by health economists as capacity to benefit from treatment [81], for increased aspirin use. However, the potential benefits from increased aspirin use in the population need to be balanced by the undesirable effects of the medicine. Perhaps, it is time for another conference on the public health potential of aspirin to be convened [82] so that this important matter can be given further consideration with a view to appropriate policy responses being developed in accordance with the evidence.

Part of this evidence base will need to take account of the existing levels of aspirin use within the population [83], which may require some surveys to be undertaken in some countries.

In addition, the natural exposure of nutraceutical salicylate through the diet might also contribute to cancer control programmes in future and further research is required. 


\section{References}

1. Sporn M (1993) Chemoprevention of cancer Lancet 342 1211-3 PMID 7901533 doi:10.1016/0140-6736(93)92189-Z

2. Surh $\mathrm{YJ}$ and Chun KS (2007) Cancer chemopreventive effects of curcumin Adv Exp Med Biol 595 149-72 PMID 17569209 doi:10.1007/978-0-387-46401-5 5

3. Hofseth LJ and Wargovich MJ (2007) Inflammation, cancer, and targets of ginseng $\mathrm{J}$ Nutr 1371 Suppl 183-5 PMID 17182823

4. Lebwohl M and Kathryn M (2006) New roles for systemic retinoids J Drugs Dermatol 55 406-9 PMID 16703775

5. Jahanzeb M (2007) Reducing the risk for breast cancer recurrence after completion of tamoxifen treatment in postmenopausal women Clin Ther 298 1535-47 PMID $\underline{17919537}$ doi: 10.1016/j.clinthera.2007.08.013

6. Flower R (2003) What are all the things aspirin does? BMJ 327 572-3 PMID 12969898 doi:10.1136/bmj.327. 7415.572

7. Sneader W (2000) The discovery of aspirin: a reappraisal BMJ 321 1591-4 PMID 11124191 doi: 10.1136/bmj.321.7276.1591

8. Baron JA (2003) Epidemiology of non-steroidal antiinflammatory drugs and cancer Prog Exp Tumor Res 37 1-24 PMID 12795046 doi:10.1159/000071364

9. Vainio H, Morgan GP and Kleihues $P$ (1997) An international evaluation of the Cancer preventive potential of nonsteroidal anti-inflammatory drugs Cancer Epidemiol Biomarkers Prev 6 749-53 PMID 9298584

10. Arber N, Eagle CJ, Spicak J, Rácz J, Dite P, Hajer J et al (2006) Celecoxib for the prevention of colorectal adenomatous polyps $N$ Engl J Med 3559 885-95 PMID 16943401 doi:10.1056/NEJMoa061652

11. Bertagnolli $M M$, Eagle $C J$, Zauber AG, Redston $M$, Solomon SD, Kim K et al (2006) Celecoxib for the prevention of sporadic colorectal adenomas $N \mathrm{Engl} \mathrm{J}$ Med 3559 873-84 PMID 16943400 doi:10.1056/ NEJMoa061355

12. Antithrombotic Trialists' Collaboration (2002) Collaborative meta-analysis of randomised trials of anti-platelet therapy for prevention of death, myocardial infarction, and stroke BMJ 324 71-86 doi:10.1136/bmj.324.7329.71

13. Kauh J and Khuri FR (2007) Can statins pass the aspirin litmus test in cancer? J Clin Oncol 2523 395-6 PMID $\underline{17687147}$ doi:10.1200/JCO.2007.11.9511

14. Pirmohamed M, James S, Meakin S, Green C, Scott AK, Walley TJ et al (2004) Adverse drug reaction as cause of admission to hospital: prospective analysis of 18, 820 patients BMJ 329 15-9 PMID 15231615 doi:10.1136/bmj. 329.7456.15

15. Sandler, RS, Halabi, S, Baron, JA, Budinger, S, Paskett, E, Keresztes, $\mathrm{R}$ et al (2003) A randomised trial of aspirin to prevent colorectal adenomas in patients with previous colorectal cancer New Engl J Med 348 883-90 PMID $\underline{12621132}$ doi:10.1056/NEJMoa021633

16. Baron JA, Cole BF, Sandler RS, Haile RW, Ahnen D, Bresalier $\mathrm{R}$ et al (2003) A randomised trial of aspirin to prevent colorectal adenomas New Engl J Med 348 891-9 PMID 12621133 doi:10.1056/NEJMoa021735

17. Gann PH, Manson JE, Glyn RJ, Buring JE and Hennekens $\mathrm{CH}$ (1993) Low-dose aspirin and incidence of colorectal tumors in a randomised trial J Natl Cancer Inst 851220 4 PMID 8331682 doi:10.1093/inci/85.15.1220

18. Cook NR, Lee IM, Gaziano JM, Gordon D, Ridker PM, Manson JE et al (2005) Low-dose aspirin in the primary prevention of cancer: the Women's Health Study: a randomised controlled trial JAMA 294 47-55 PMID 15998890 doi:10.1001/jama.294.1.47

19. Flossmann E and Rothwell PM (2007) Effect of aspirin on long-term risk of colorectal cancer: consistent evidence from randomised and observational studies Lancet 369 1603-13 PMID 17499602 doi:10.1016/S0140$\underline{6736(07) 60747-8}$

20. Blacklock CJ, Lawrence JR, Wiles D, Malcolm EA, Gibson $\mathrm{IH}$, Kelly CJ and Paterson JR (2001) Salicylic acid in the serum of subjects not taking aspirin. Comparison of salicylic acid concentrations in the serum of vegetarians, non-vegetarians, and patients taking low dose aspirin J Clin Pathol 547 553-5 PMID 11429429 doi:10.1136/jicp.54.7.553

21. Morgan GP (2003) Should aspirin be used to counteract salicylate deficiency? Pharmacol Toxicol 93 153-5 doi:10.1034/j.1600-0773.2003.930401.x

22. Kalra EK (2003) Nutraceutical-definition and introduction AAPS Pharm Sci 52 e25 PMID 14621960 doi:10.1208/ps050325

23. Brower $V$ (2005) A nutraceutical a day may keep the doctor away EMBO Rep 86 708-11 PMID 16065061 doi:10.1038/sj.embor.7400498

24. Bjelakovic G, Nikolova D, Gluud LL, Simonetti RG and Gluud C (2008) Antioxidant supplements for prevention of mortality in healthy participants and patients with various diseases Cochrane Database Syst Rev 162 CD007176 PMID 18425980

25. Spitzberg VL (2005) Invited review: Bovine milk fat globule membrane as a potential nutraceutical $J$ Dairy Sci 887 2289-94 PMID 15956291 doi:10.3168/jds.S00220302(05)72906-4 
26. Jankun J, Selman SH, Aniola J and Skrzypczak-Jankun E (2006) Nutraceutical inhibitors of urokinase:potential applications in prostate cancer prevention and treatment Oncol Rep 162 341-6 PMID 16820913

27. Watkins BA, Li Y and Seifert MF (2001) Nutraceutical fatty acids as biochemical and molecular modulators of skeletal biology $J$ Am Coll Nutr $20 \quad 5 \quad 410-6 \quad$ PMID 11603651

28. Mantovani A, Allavena P, Sica A and Balkwill F (2008) Cancer-related inflammation Nature 24 436-44 PMID $\underline{18650914}$ doi:10.1038/nature07205

29. Elkind MS (2006) Inflammation, atherosclerosis, and stroke (Review) Neurologist 123 140-8 PMID 16688015 doi:10.1097/01.nrl.0000215789.70804.b0

30. Hansson GK (2005) Inflammation, atherosclerosis, and coronary artery disease New Engl J Med 352 1685-95 PMID 15843671 doi:10.1056/NEJMra043430

31. Rayner G, Hawkes C, Lang T and Bello W (2006) Trade liberalization and the diet transition: a public health response Health Promot Int 21 Suppl 1 67-74 PMID $\underline{17307959}$

32. Gotzsche PC and Nielsen M (2006) Screening for breast cancer with mammography Cochrane Database Syst Rev 184 CD001877 PMID 17054145

33. Mangiapane S, Blettner $M$ and Schlattmann $P$ (2008) Aspirin use and breast cancer risk: a meta-analysis and meta-regression of observational studies from 2001 to 2005 Pharmacoepidemiol Drug Saf 172 115-24 PMID 17955496 doi:10.1002/pds.1503

34. Zhang SM, Cook NR, Manson JE, Lee IM and Buring JE (2008) Low-dose aspirin and breast cancer risk:results by tumour characteristics from a randomised trial $\mathrm{Br} \mathrm{J}$ Cancer 985 989-91 PMID 18268496 doi:10.1038/sj.bjc. $\underline{6604240}$

35. Chun J, Pocock B, Joseph KA, El-Tamer M, Klein L and Schnabel $F$ (2008) Breast cancer risk factors in younger and older women Ann Surg Oncol 16 96-9 PMID 18979140 doi:10.1245/s10434-008-0176-8.

36. Hoskins KF, Zwaagstra A and Ranz M (2006) Validation of a tool for identifying women at high risk for hereditary breast cancer in population-based screening Cancer Res 1078 1769-76 PMID 16967460

37. Hewitson $P$, Glasziou $P$, Irwig L, Towler B and Watson E (2007) Screening for colorectal cancer using the faecal occult blood test, Hemoccult Cochrane Database Syst Rev 241 CD001216 PMID 17253456

38. Dunlop MG, British Society for Gastroenterology, and Association of Coloproctology for Great Britain and Ireland (2002) Guidance on gastrointestinal surveillance for hereditary non-polyposis colorectal cancer, familial adenomatous polypolis, juvenile polyposis, and PeutzJeghers Gut 51 Suppl 5 21-7 PMID 12221036 doi: 10.1136/gut.51.suppl 5.v21

39. Sahni VA and Burling D (2007) The new NHS colorectal cancer screening programme and the potential role of radiology? Br J Radiol 80958 778-81 PMID 17959921 doi:10.1259/bjr/69940604

40. Agrawal J and Syngal S (2005) Colon cancer screening strategies Curr Opin Gastroenterol 21 1 59-63 PMID $\underline{15687886}$

41. Worthley DL, Smith A, Bampton PA and Young GP (2006) Many participants in fecal occult blood test population screening have a higher-than-average risk for colorectal cancer Eur J Gastroenterol Hepatol 1810 1079-83 PMID 16957514 doi:10.1097/01.meg. $\underline{0000231754.35340 . f a}$

42. Boggs BD, Stephens MM and Wallace R (2005) How does colonoscopy compare with fecal occult blood testing as a screening tool for colon cancer J Fam Pract 5411 996-7 PMID 16266608

43. Dobson $R$ (2007) Less than half of men invited for screening for bowel cancer take up the offer, project shows Br Med J 3351115 doi:10.1136/bmj.39413.623009. $\underline{\mathrm{DB}}$

44. West NJ, Poullis AP and Leicester RJ (2008) The NHS Bowel Cancer Screening Programme-a realistic approach with additional benefits Colorectal Dis 10708 14 PMID 17956587 doi:10.1111/j.1463-1318.2007.01396.x

45. Kennedy A, Rogers and Bower P (2007) Support for selfcare for patients with chronic disease BMJ 335 968-70 PMID 17991978 doi:10.1136/bmj.39372.540903.94

46. Elwood P, Morgan GP, Brown G and Pickering J (2005) Aspirin for all over 50? BMJ 330 1440-1 doi:10.1136/ bmi.330.7505.1440

47. Bulugahapitiya U, Siyambalapitiya S, Sithole J, Fernando DJ and Idris I (2008) Age threshold for routine aspirin treatment to prevent cardiovascular disease in patients without diabetes Heart 94 1429-32 PMID 18708419 doi:10.1136/hrt.2008.150698

48. Baigent $C$ (2005) Aspirin for all over 50 ? (against) $B M J$ 330 1442-3 doi:10.1136/bmj.330.7505.1442

49. Hennekens $\mathrm{CH}$ (2007) Aspirin in the treatment and prevention of cardiovascular disease: current perspectives and future directions Curr Atheroscler Rep 95 409-16 PMID 18001625 doi:10.1007/s11883-0070053-0

50. Romeri E, Baker A and Griffiths C (2006) Mortality by deprivation and cause of death in England and Wales, 1999 to 2003 Health Stat Q Winter 19-34 PMID 17165467 
51. Mucha L, Stephenson J, Morandi N and Dirani R (2006) Meta-analysis of disease risk associated with smoking, by gender and intensity of smoking Gend Med 34279 91 PMID 17582369 doi:10.1016/S1550-8579(06)80216-0

52. Quentin W, Neubauer S, Leidl R and Konig HH (2007) Advertising bans as a means of tobacco control policy:a systematic literature review of time-series analyses Int J Public Health $52 \quad 5 \quad 295-307$ PMID $\underline{18030945}$

53. Mukamal KJ (2006) The effects of smoking and drinking on cardiovascular disease and risk factors Alcohol Res Health 293 199-202 PMID 17373409

54. Ebbert JO, Janney CA, Sellers TA, Folsom AR and Cerhan JR (2005) The association of alcohol consumption with coronary heart disease mortality and cancer incidence varies by smoking history J Gen Intern Med 201 14-20 PMID 15693922 doi:10.1111/j.1525-1497.2005.40129.x

55. Gonzalez CA and Riboli E (2006) Diet and cancer prevention: where we are, where we are going Nutr Cancer $56 \quad 2$ 225-31 PMID 17474869 doi:10.1207/ s15327914nc5602 14

56. Gonzalez CA (2006) The European Prospective Investigation into Cancer and Nutrition (EPIC) Public Health Nutr 9 1A 124-6 PMID 16512959 doi:10.1079/ PHN2005934

57. World Cancer Research Fund (2007) Food, nutrition, physical activity and the prevention of cancer, available at http://www.wcrf-uk.org/research science/ recommendations.lasso (accessed 1 December 2007)

58. Flegal KM, Graubard BI, Williamson DF and Gail $\mathrm{MH}$ (2007) Cause-specific excess deaths associated with underweight, overweight, and obesity JAMA 298 202837 PMID 17986696 doi:10.1001/jama.298.17.2028

59. Barbour V, Chinnock P, Peiperl L, Veitch E and Yamey G (2008) From Theory to Practice: Translating Research into Health Outcomes PLoS Med 51 e15 PMID 18184034 doi:10.1371/journal.pmed.0050015

60. Wakefield AJ, Murch SH and Antony A (1998) Ileal lymphoid-nodular hyperplasia, non-specific colitis and pervasive developmental disorders in children Lancet 351 637-41 PMID 9500320 doi:10.1016/S0140-6736 (97)11096-0

61. Nagaraj A (2006) Does qualitative synthesis of anecdotal evidence with that from scientific research help in understanding public health issues:a review of Iow MMR uptake Eur J Public Health 161 85-8 PMID 16446303 doi:10.1093/eurpub/cki058

62. Markowitz LE, Dunne EF, Saraiva M, Lawson HW, Chesson $\mathrm{H}$ and Unger ER (2007) Centers for Disease Control and Prevention (CDC); Advisory Committee on
Immunisation Practices (ACIP) MMWR Recomm Rep 56 RR-2 1-24 PMID 17380109

63. Schiller JT and Lowy DR (2006) Prospects for cervical cancer prevention by human papillomavirus vaccination Cancer Res 6621 10229-32 PMID 17079437 doi:10.1158/0008-5472.CAN-06-0630

64. Thomas T and Lambert S (2008) An ethnographic study of intermediate care service in Wales: the hidden work J Nurs Manag 16 181-7 PMID 18269549 doi:10.1111/i. 1365-2834.2008.00846.x

65. Healy J, Victor CR, Thomas A and Seargeant J (2002) Professionals and post-hospital care for older people $\mathrm{J}$ Interprof Care 161 19-29 PMID 11915713 doi:10.1080/ 13561820220104131

66. Entwistle VA and Watt IS (2006) Patient involvement in treatment decision-making: The case for a broader conceptual framework Patient Educ Couns 63 268-78 PMID 16875797 doi:10.1016/j.pec.2006.05.002

67. Davis RE, Jacklin R, Sevdalis N and Vincent CA (2007) Patient involvement in patient safety: what factors influence patient participation and engagement? Health Expect 10 259-67 PMID 17678514 doi:10.1111/j.13697625.2007.00450.x

68. Kennedy $L$ (2006) How long do we want to live and at what cost? Br J Cardiol 133 165-7

69. Berridge $V$ and Gorsky $M$ (2004) The importance of the past in public health $\mathrm{J}$ Epidemiol Community Health $\mathbf{5 8}$ 728-9 PMID 15310793 doi:10.1136/jech.2003.019141

70. Hamlin C and Sheard S (1998) Revolutions in public health: 1848, and 1998? BMJ 317 587-91 PMID 9721121

71. Sram I and Ashton J (1998) Millennium report to Sir Edwin Chadwick BMJ 317 592-6 PMID 9721122

72. Albert T (2004) Public health goes private Lancet $\mathbf{3 6 3}$ 2008 PMID 15194274 doi:10.1016/S0140-6736(04)16433-7

73. Webster C (1996) Public health in decline Healthmatters 11 10-1

74. Nurse $\mathrm{J}$ and Edmondson-Jones $\mathrm{P}$ (2007) A framework for the delivery of public health: an ecological approach $\mathrm{J}$ Epidemiol Community Health 61 555-8 PMID 17496266 doi:10.1136/jech.2005.039073

75. Umble K, Steffen D, Porter J., Miller D, HummerMcLaughlin K, Lowman A and Zelt S (2005) The National Public Health Leadership Institute: evaluation of a team-based approach to developing collaborative public health leaders Am J Public Health 954 641-4 PMID 15798124 doi:10.2105/AJPH.2004.047993

76. Endslay S, Kirkegaar M and Linares A (2005) Working together: communities of practice in family medicine Fam Pract Manag 121 28-32 PMID 15709520 
77. Khaw HT, Wareham N, Bingham S, Welsh A and Luben R (2008) Combined impact of health behaviours and mortality in men and women: the EPIC-Norfolk Prospective Population Study PLoS Med 51 e12. PMID 18184033 doi:10.1371/journal.pmed.0050012 doi:10.1371/journal.pmed.0050012

78. Morgan G (2008) Ethical considerations on aspirin prophylaxis Qual Prim Care 16 433-40 PMID 19094419

79. McConnel $C$ and Turner $L$ (2005) Medicine, ageing and human longevity EMBO Rep 6 S1 S59-62 PMID 15995665 doi:10.1038/sj.embor.7400431

80. Steel N, Bachmann M, Maisey S, Shekelle P, Breeze E, Marmot $M$ and Melzer D (2008) Self reported receipt of care consistent with 32 quality indicators: national population survey of adults aged $\mathbf{5 0}$ or more in England BMJ 337 a957 PMID 18703659 doi:10.1136/bmj. $\underline{\text { a957 }}$

81. Clarke CM (2001) Rationing scarce life-sustaining resources on the basis of age J Adv Nurs 355 799-804 PMID 11529983 doi:10.1046/j.1365-2648.2001.01913.x

82. Morgan GP (2005) What next for low-dose aspirin? J Epidemiol Community Health 59 1 3-4 PMID 15598718 doi:10.1136/jech.2004.026260

83. Pignone M, Anderson GK and Binns K (2007) Aspirin use among adults over 40 in the US: Results of a national survey $A m \mathrm{~J}$ Prev Med 32 403-7 PMID 17478266 doi:10.1016/i.amepre.2007.01.010 